LAWRENCE LIVERMORE NATIONAL LABORATORY
Evaluation of Cavity Collapse and Surface Crater Formation for Selected Lawrence Livermore National Laboratory Underground Nuclear Tests - 2010

Gayle A. Pawloski

December 28, 2010 


\section{Disclaimer}

This document was prepared as an account of work sponsored by an agency of the United States government. Neither the United States government nor Lawrence Livermore National Security, LLC, nor any of their employees makes any warranty, expressed or implied, or assumes any legal liability or responsibility for the accuracy, completeness, or usefulness of any information, apparatus, product, or process disclosed, or represents that its use would not infringe privately owned rights. Reference herein to any specific commercial product, process, or service by trade name, trademark, manufacturer, or otherwise does not necessarily constitute or imply its endorsement, recommendation, or favoring by the United States government or Lawrence Livermore National Security, LLC. The views and opinions of authors expressed herein do not necessarily state or reflect those of the United States government or Lawrence Livermore National Security, LLC, and shall not be used for advertising or product endorsement purposes.

\section{Auspices Statement}

This work performed under the auspices of the U.S. Department of Energy by Lawrence Livermore National Laboratory under Contract DE-AC52-07NA27344. 


\title{
Evaluation of Cavity Collapse and Surface Crater Formation for Selected Lawrence Livermore National Laboratory Underground Nuclear Tests - 2010
}

\author{
Gayle Pawloski \\ Atmospheric, Earth and Energy Division \\ Physical and Life Sciences Directorate
}

December 28, 2010

Lawrence Livermore National Laboratory

Livermore, CA 94551 


\section{Evaluation of Cavity Collapse and Surface Crater Formation for Selected Lawrence Livermore National Laboratory Underground Nuclear Tests - 2010}

This report evaluates collapse evolution for selected Lawrence Livermore National Laboratory (LLNL) underground nuclear tests at the Nevada National Security Site (NNSS, formerly called the Nevada Test Site). The work is being done at the request of Navarro-Interra LLC, and supports environmental restoration efforts by the Department of Energy, National Nuclear Security Administration for the Nevada Site Office. Safety decisions must be made before a surface crater area, or potential surface crater area, can be reentered for any work. Our statements on cavity collapse and surface crater formation are input into their safety decisions. These statements do not include the effects of erosion that may modify the surface collapse craters over time. They also do not address possible radiation dangers that may be present.

Subject matter experts from the LLNL Containment Program who had been active in weapons testing activities performed these evaluations. Information used included drilling and hole construction, emplacement and stemming, timing and sequence of the selected test and nearby tests, geology, yield, depth of burial, collapse times, surface crater sizes, cavity and crater volume estimations, and ground motion. Both classified and unclassified data were reviewed. Various amounts of information are available for these tests, depending on their age and other associated activities. Lack of data can hamper evaluations and introduce uncertainty. We make no attempt to quantify this uncertainty.

The following unclassified summary statements describe collapse evolution and crater stability in response to the 2010 request to review 4 LLNL test locations in areas 2, 9 and 10 of Yucca Flat: Mullet in U2ag, Hod-B (Red) in U9 its x-20, Eagle in U9av, and Tub-D in U10aj D. 


\section{Mullet \\ U2ag}

The LLNL-sponsored Mullet test was detonated in U2ag on October 17, 1963. Mullet, a safety experiment with an announced yield of low (less than $20 \mathrm{kt}$ ) (DOE/NV-REV 15 ${ }^{1}$ ), was detonated in alluvium at a working point of about $60 \mathrm{~m}$ below the surface. U2ag is located in east-central Area 2 between the Carpetbag Fault to the west and the Yucca Fault to the east. Nearby tests include Kennebec in U2af on June 25, 1963; Pongee in U2ah on July 22, 1965; Commodore in U2am on May 20, 1967; and Stanyan in U2aw on September 26, 1974.

There was an early-time radiochemistry sampling system that went from the emplacement hole to sampling equipment at the surface. It is associated with CAU 547 CAS 02-37-02. This site has been a discussion point with the NSTec Borehole Management Program.

We have reviewed geology and test-related data for Mullet, including information on the cavity. We know that:

- Mullet, a safety experiment, did not collapse to the surface. It was emplaced in a cased hole. It had no associated post-test drilling.

- With the working point in alluvium in Area 2 it is hard to predict where subsurface collapse for the announced yield might terminate.

- Mullet in U2ag is located in a well-used testing area and surrounded by many tests, some of them relatively large. The ground surface at the U2ag site has not changed over the 29 years of subsequent ground motion caused by underground testing.

We have reviewed geology and test-related data, including information on the cavity and subsequent subsurface collapse. We don't know if the subsurface collapse has changed over time, nor can we preclude that small, additional collapses have or have not occurred. Ground motion from many subsequent tests gives credibility that collapse is complete and permits us to conclude that the current configuration may be stable. Due to lack of complete collapse to the surface, however, LLNL has less confidence than normal in making this statement. We rely on DOE/NNSA/NSO to make decisions concerning safety issues related to reentering potential crater areas.

\footnotetext{
${ }^{1}$ DOE (U.S. Department of Energy), 2000, United States Nuclear Tests July 1945 through September 1992, U.S. Department of Energy, Nevada Operations Office, Las Vegas, NV, DOE/NV-209, Rev 15.
} 


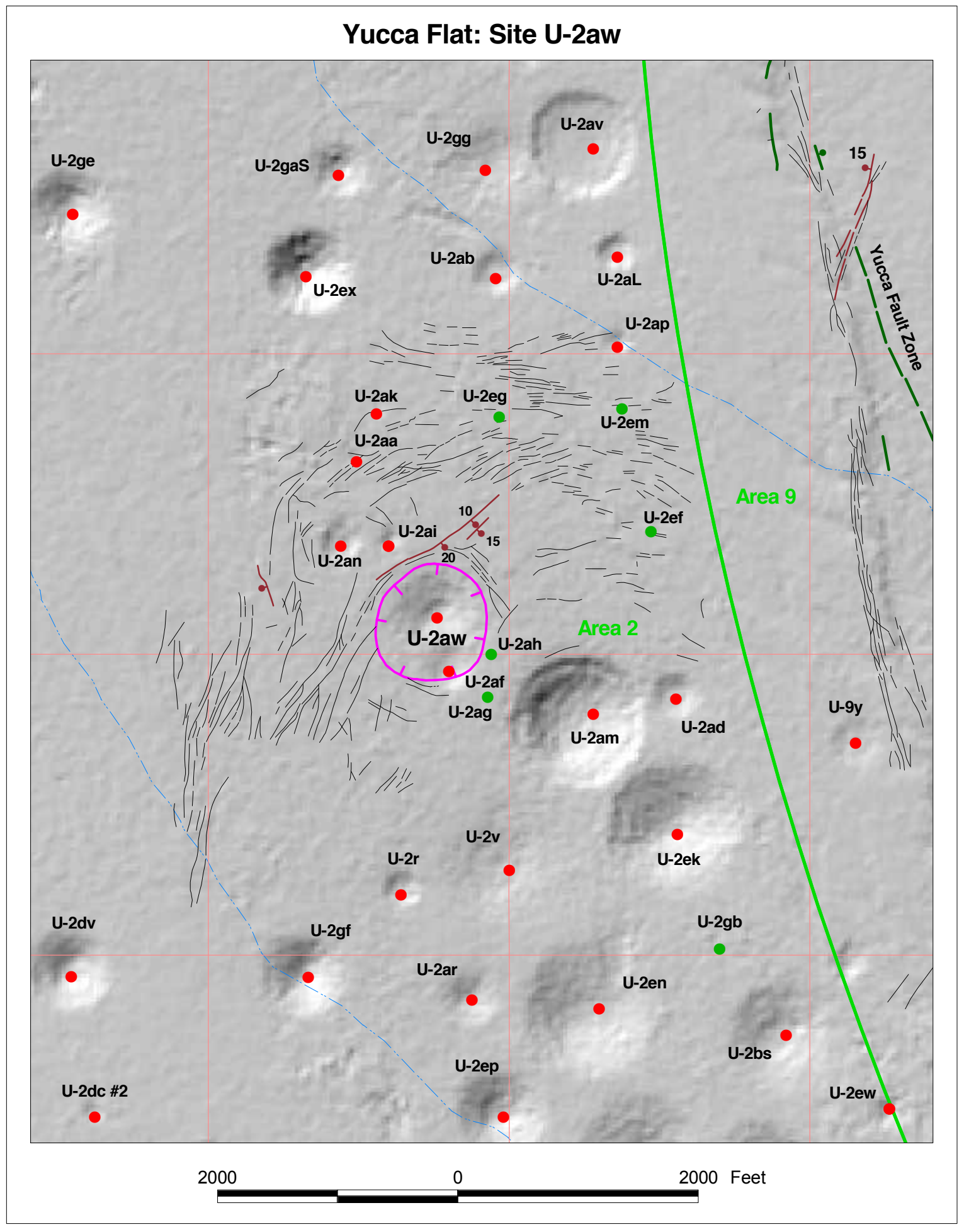

Surface effects map of U2aw, also showing the location of U2ag (Grasso, 2003). 


\section{Hod-B (Red)}

\section{U9its $x-20$}

The LLNL-sponsored Hod-B (Red) test was detonated in U9its X-20 on May 1, 1970. It was one of two detonations occurring simultaneously in separate holes - the other was Hod-A (Green) in U9its $x-23$. Hod-B, with an announced yield of $<20 \mathrm{kt}$ (DOE/NV-REV 15), was detonated in tuff at a working point of $265 \mathrm{~m}$ below the surface.

The Area 9 ITS area is located in northeastern Area 9 east of the Yucca Fault and west of the Area 9 Fault, near the eastern border of the NNSS. This region of Area 9 was identified to meet specific program needs by closely locating tests within an organized grid spacing. There were twenty-six detonations in the Area 9 ITS area from 1970 to 1972, with many of them occurring as sets of simultaneous detonations.

Hod-C (Blue) in U9its z-25 was detonated about 15 minutes before Hod A and B. The Hod tests, located near the southern boundary of the area, were the third group of tests detonated within the Area 9 ITS area.

Nearby detonations include Scree Alhambra in U9its z-21 on 13-Oct-1970; Avens Asmalte in U9its w-21 on 16-Dec-1970; Haplopappus in U9its w-22 on 28-Jun-1972; Handicap in U9ba on March 12, 1964; and Bunker in U9bb on February 13, 1964.

Hod-B collapsed to the surface about 9 minutes after detonation. It formed a crater about $13 \mathrm{~m}$ deep and about $169 \mathrm{~m}$ in diameter. There was one post-test hole associated with Hod-B, located within the collapse crater. There was an accidental release of radioactivity detected onsite only associated with the Hod-A and Hod-B detonations.

We have reviewed geology and test-related data, including information on the cavity, and believe that complete collapse occurred soon after detonation. The number of subsequent tests in Yucca Flat and tight spacing of tests in the Area 9 ITS area gives us comfort that cavity collapse should be complete. The ground surface above the U9its X-20 site has not changed over time, so it seems reasonable to conclude that the current configuration is stable. We have evaluated crater stability produced from cavity collapse, and have not considered later erosion effects. We rely on NSTec and DOE/NNSA/NSO to make decisions concerning safety issues related to reentering the crater area. 


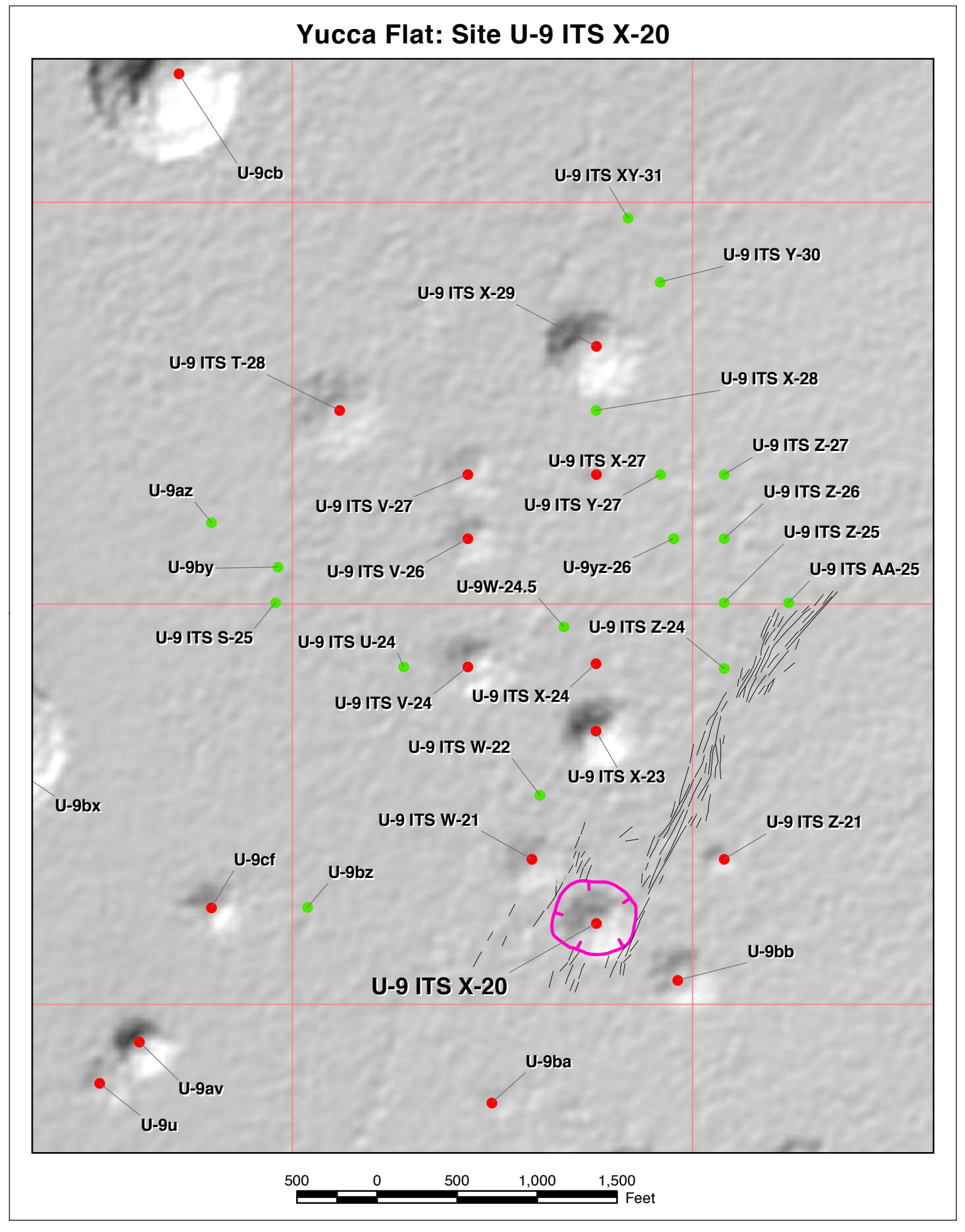

Surface effects map of U9its x-20 (Grasso, 2003). 


\section{Eagle \\ U9av}

The LLNL sponsored Eagle test was detonated in hole U9av on December 12, 1963. Eagle had an announced yield of $5.3 \mathrm{kt}$ (DOE/NV209-REV 15). It was detonated in alluvium at a working point of $168 \mathrm{~m}$ below the surface. U9av is located in central Area 9 between the Yucca Fault to the west and the Area 9 Fault to the east. U9av is southwest of the Area 9 ITS region. Nearby tests include: Vat in U9cf on October 10, 1968; Mustang in U9at on November 15, 1963; Raritan in U9u on September 6, 1962; and Pleasant in U9ah on May 29, 1963.

Eagle collapsed to the surface in about $3 \frac{1}{2}$ minutes after detonation. It formed a crater about $18 \mathrm{~m}$ deep and about $122 \mathrm{~m}$ in diameter. Vertical satellite hole U9av \#1 was drilled to $183 \mathrm{~m}$ and instrumented for the test; it was within the collapse crater. There were 2 slant post-test holes: PS 3 was drilled to $222 \mathrm{~m}$ and PS 4 was drilled to $230 \mathrm{~m}$. Eagle had an accidental release of radioactivity detected offsite.

We have reviewed geology and test-related data, including information on the cavity and crater, and believe that complete collapse occurred quickly after detonation. The number of subsequent tests on Yucca Flat, and the entire NNSS, gives us comfort that cavity collapse and crater formation should be complete. The ground surface above the U9av site has not changed over time, so it seems reasonable to conclude that the current configuration is stable. We have evaluated crater stability produced from cavity collapse, and have not considered later erosion effects. We rely on NSTec and DOE/NNSA/NSO to make decisions concerning safety issues related to reentering the crater area. 


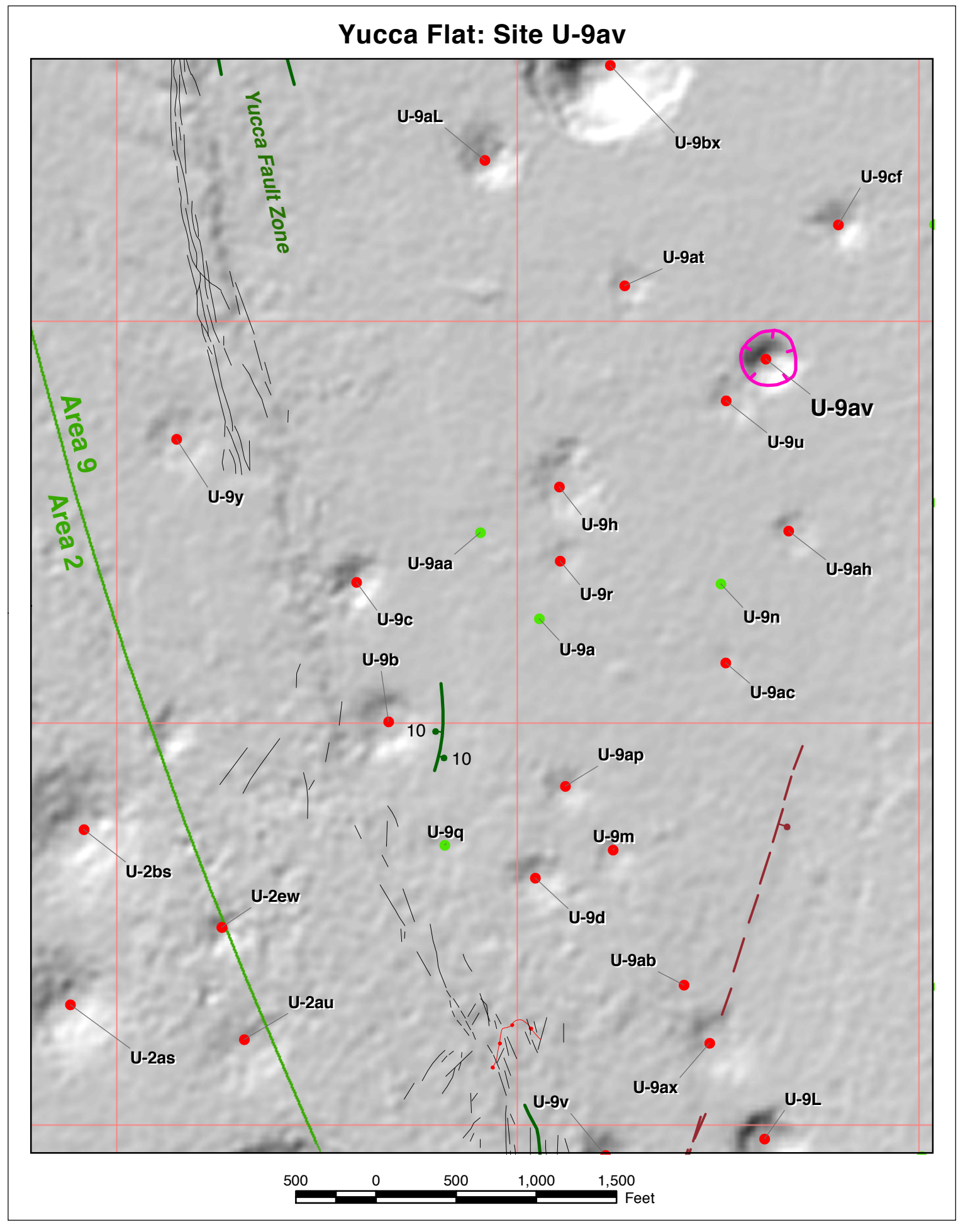

Surface effects map of U9av (Grasso, 2003). 


\section{Tub-D \\ U10aj D}

The LLNL-sponsored Tub-D test was detonated in U10aj D on June 6, 1968. It was one of five detonations occurring simultaneously in separate holes, including Tub-A in U10aj C, Tub-B in U10aj B, Tub-C in U10aj F, and Tub-F in U10aj A. Each Tub detonation had an announced yield of $<20 \mathrm{kt}$ (DOE/NV-REV 15). Tub-D was detonated in tuff at a working point of $274 \mathrm{~m}$ below the surface.

The Tub detonations are located close together in west central Area 10 in a well-used testing area east of the Yucca Fault. Other nearby tests include Uncle, a crater test considered the first underground test at the Nevada Test Site on November 29, 1951; Ess, a crater test on March 23, 1955; Vito in U10ab on July 14, 1967; Rivet I in U10aa on January 18, 1967; Rivet II in U10z on January 26, 1967; Rivet III in U10y on March 2, 1967; Ward in U10x on February 8, 1967; Rovena in U10s on August 10, 1966; and Newark in U10u on September 29, 1966.

Tub-A and Tub-B collapsed to the surface in about 10 minutes each, and both display surface craters. Tub-C collapsed to the surface with a minor crater. Tub-D and Tub-F did not collapse to the surface. There is information that Tub-D had a subsurface collapse at about 26 minutes.

We have reviewed geology and test-related data, including information on the cavity and subsequent subsurface collapse for Tub-D. We don't know if the subsurface collapse has changed over time, nor can we preclude that small, additional collapses have or have not occurred. Ground motion from many subsequent tests gives credibility that collapse is complete and permits us to conclude that the current configuration may be stable. Due to lack of complete collapse to the surface, however, LLNL has less confidence than normal in making this statement. We rely on DOE/NNSA/NSO to make decisions concerning safety issues related to reentering potential crater areas. 


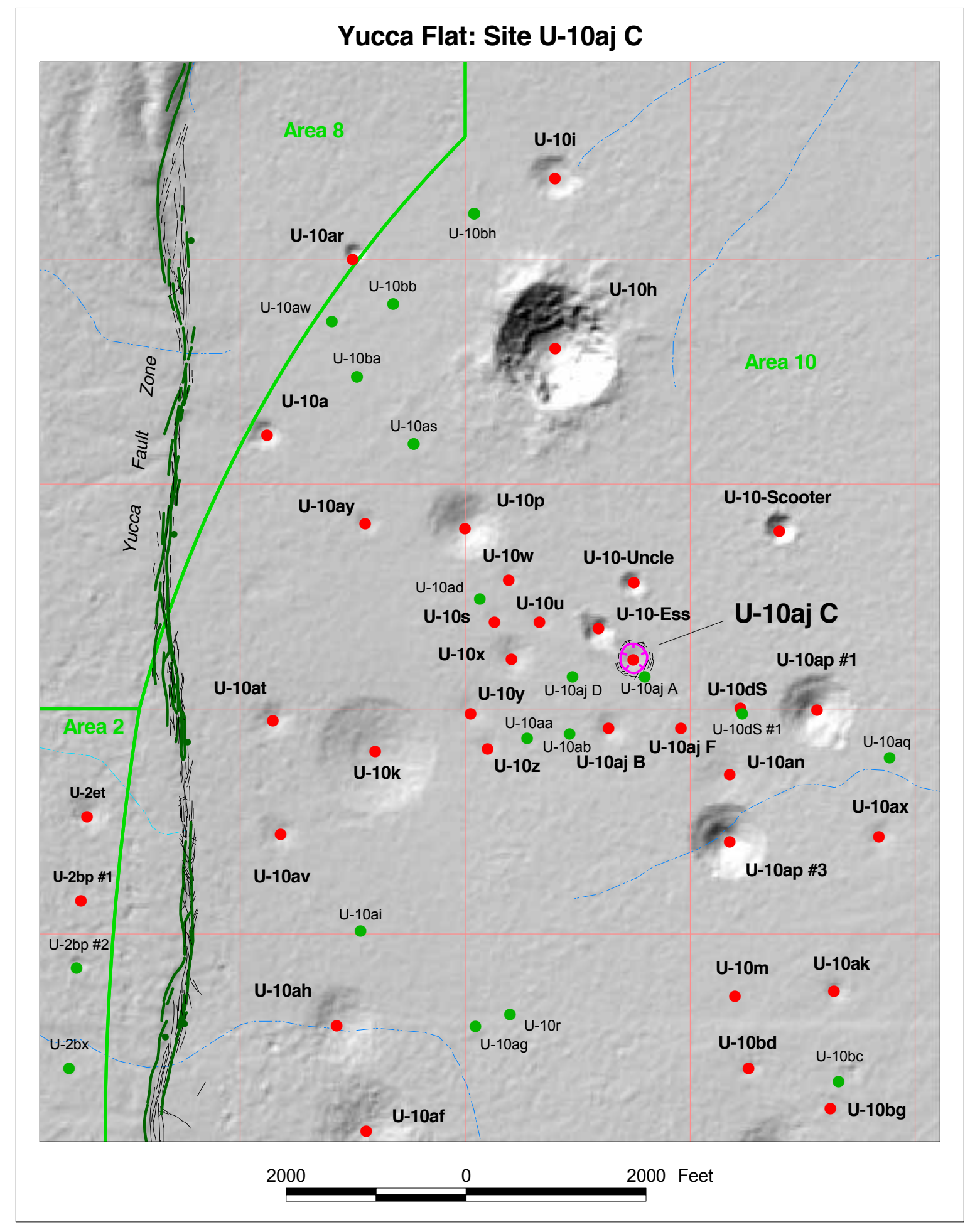

Surface effects map of U10aj C, also showing the location of U10aj D (Grasso, 2003). 